\title{
Concepções acerca da Educação em Direitos Humanos: um estudo com professores de educação infantil
}

\author{
Conceptions about Human Rights Education: a study with \\ preschool teachers
}

\section{Concepciones sobre la Educación en Derechos Humanos: un estudio con profesores de educación infantil}

\author{
Talita Santana Maciel ${ }^{1}$ \\ ORCID: https://orcid.org/0000-0002-6846-8684. \\ E-mail: talita.s.maciel@hotmail.com \\ Tânia Suely Antonelli Marcelino Brabo ${ }^{2}$ \\ ORCID: https://orcid.org/0000-0002-9833-0635. \\ E-mail: tamb@unesp.com.br
}

Resumo: O presente artigo resulta de pesquisa científica que constatou e discutiu concepções de professores de educação infantil acerca da educação em direitos humanos - campo de estudos e subárea da educação reconhecida por meio de políticas públicas nacionais, documentos internacionais, e que representa a luta pela efetivação de uma cultura de direitos humanos. Como procedimentos metodológicos adotou-se a pesquisa de campo e a pesquisa bibliográfica, com foco em referencial teórico que concebe a educação em direitos humanos a partir de uma perspectiva histórico-crítica. A coleta de dados deu-se por meio de entrevista semiestruturada e questionário, e a técnica de análise de conteúdo norteou a análise dos dados. Os resultados da pesquisa indicaram que algumas das noções sobre a educação em direitos humanos que possuem os sujeitos entrevistados relacionam-se à justificativa moral dos direitos humanos; outras apontam para a dimensão da formação ética ou formação para a cidadania na acepção clássica; outras, ainda, referenciam uma concepção errônea de que direitos humanos não deveriam proteger a todos e todas, representando a expressão de uso popular de que direitos humanos são para humanos direitos. A partir dos resultados, foi possível concluir que os conhecimentos do professorado em relação à educação em direitos humanos são insuficientes e esse fato deve-se à formação docente que tiveram acesso.

Palavras-chave: Educação. Direitos humanos. Formação docente.

Abstract: This article is the result of scientific research that found and discussed the conceptions of preschool teachers about human rights education - a field of study and subarea of education recognized through national public policies, international documents, and representing the struggle for the realization of a culture of human rights. The methodological procedures were field research and bibliographic research, focusing on the theoretical framework that conceives human rights education from a historical-critical perspective. Data were collected through semi-structured interviews and questionnaires, and the content analysis technique guided the data analysis. The research results indicated that some of the notions about human rights education that the subjects interviewed possess relate to the moral justification of human rights; others point to the dimension of ethical formation or citizenship formation in the classical view; still others refer to a misconception that human rights should not protect everyone, representing the popular expression that human rights are for correct

\footnotetext{
${ }^{1}$ Universidade Estadual Paulista "Júlio de Mesquita Filho" (UNESP). Marília/SP, Brasil.

2 Universidade Estadual Paulista "Júlio de Mesquita Filho" (UNESP). Marília/SP, Brasil.
} 
humans. From the results, it was possible to conclude that the teachers' knowledge about human rights education is insufficient and this fact is due to the teacher education they had access to.

Key words: Education. Human rights. Teacher training.

Resumen: Este artículo es el resultado de una investigación científica que encontró y discutió las concepciones de los professores de educación infantil sobre la educación en derechos humanos, un campo de estudio y subárea de educación reconocida a través de políticas públicas nacionales, documentos internacionales y que representa la lucha por la realización de una cultura de derechos humanos. Los procedimientos metodológicos adoptados fueron la investigación de campo y la investigación bibliográfica, centrándose en el marco teórico que concibe la educación en derechos humanos desde una perspectiva histórica-crítica. Los datos se recopilaron a través de entrevistas y cuestionarios semiestructurados, y la técnica de análisis de contenido guió el análisis de datos. Los resultados de la investigación indicaron que algunas de las nociones sobre la educación en derechos humanos que poseen los sujetos entrevistados se relacionan con la justificación moral de los derechos humanos; otros señalan la dimensión de la formación ética o la formación de ciudadanía en el sentido clásico; otros se refieren a una idea errónea de que los derechos humanos no deberían proteger a todos, lo que representa la expresión popular de que los derechos humanos son para humanos correctos. A partir de los resultados, fue posible concluir que el conocimiento de los docentes en relación con la educación en derechos humanos es insuficiente y este hecho se debe a la educación docente a la que tuvieron acceso.

Palablas clave: Educación. Derechos humanos. Formación docente.

\section{INTRODUÇÃO}

O presente texto tem como objetivo apresentar os principais resultados de uma pesquisa científica realizada entre os anos de 2016 a 2018, na cidade de Marília, interior de São Paulo, que constatou e discutiu concepções de professores de educação infantil acerca da educação em direitos humanos (MACIEL, 2018) ${ }^{3}$.

A relevância da pesquisa reside em dar a conhecer significados atribuídos por professores no que diz respeito à educação em direitos humanos (EDH), um campo de estudos e subárea da educação reconhecida por meio de políticas públicas nacionais, documentos internacionais, e que representa a luta pela efetivação de uma cultura de direitos humanos, de promoção da justiça social, de situações relacionadas à paz, à prática da tolerância, à formação para a cidadania e para o respeito às diversidades. Além disso, este trabalho está entre as poucas pesquisas científicas realizadas na área da educação em direitos humanos no Brasil e reúne condições para contribuir em estudos acadêmicos posteriores.

\footnotetext{
${ }^{3}$ O objetivo geral da pesquisa relatada neste artigo foi: verificar quais as concepções de professores(as) de educação infantil acerca da educação em direitos humanos em uma escola pública municipal da cidade de Marília, e discuti-las a partir das bases presentes nos documentos nacionais que orientam a educação em direitos humanos. Porém, em virtude do limite de páginas, este artigo não abordará a pesquisa documental, focando apenas nos resultados referentes à pesquisa de campo.
} 
Utilizamos como referencial teórico produções que concebem a educação em direitos humanos numa perspectiva histórico-crítica, por considerá-la, assim como Candau et al. (2013), orientada à afirmação da democracia e à construção de uma cultura de direitos humanos que contemple todos os âmbitos e atores sociais.

A abordagem da pesquisa foi a qualitativa, e é importante destacar que, embora a ênfase da análise nesta abordagem esteja nas inferências sobre as mensagens anunciadas juntamente com o contexto em que foram emitidas, "a análise qualitativa não rejeita toda e qualquer forma de quantificação" (BARDIN, 2002, p. 115). Assim, houve utilização de dados quantitativos.

O planejamento e execução da entrevista e do questionário (principais instrumentos de coleta de dados utilizados neste estudo) estiveram pautados nas considerações de Rosa e Arnoldi (2008), enquanto a análise dos dados teve como norte a técnica de análise de conteúdo, cujas orientações de aplicação são encontradas nos escritos de Bardin (2002) e Franco (2008).

Realizamos um levantamento de todas as escolas públicas municipais de educação infantil da cidade de Marília por meio de consultas ao blog da Secretaria da Educação do município e foram encontradas 27 unidades. Dentre as 27 , uma única escola foi sorteada de maneira aleatória para a realização da coleta de dados, que ocorreu entre os meses de setembro a novembro do ano de 2016.

A escola sorteada fica localizada na zona sul da cidade de Marília e a maioria das crianças por ela atendida compõe famílias cuja renda não ultrapassa dois salários mínimos ${ }^{4}$. Possui um quadro de 22 professores, dentre os quais todos foram recrutados a participar da pesquisa, mas somente 15 aceitaram: 14 mulheres e 1 homem. A média de idade dos sujeitos da pesquisa é de 40 anos. Dois dos professores possuem apenas o curso de Magistério, enquanto o restante possui formação em Pedagogia ${ }^{5}$.

Optamos pela entrevista semiestruturada, pois, como afirmam Rosa e Arnoldi (2008), é um instrumento que permite a obtenção de uma organização lógica dos

\footnotetext{
${ }^{4}$ A visão governamental das classes sociais, utilizada pelo Instituto Brasileiro de Geografia e Estatística (IBGE) no Censo Populacional a cada dez anos, é baseada no número de salários mínimos. Assim, a sociedade é dividida em cinco classes sociais, dentre as quais a mais baixa é calculada em até dois salários mínimos. A população caracterizada nesta pesquisa pertence, segundo esta definição oficial de classe social, à "classe E" (que se encontra na base da pirâmide social, como a grande maioria do povo brasileiro).

${ }^{5}$ Esta pesquisa foi aprovada pelo Comitê de Ética em Pesquisa com seres humanos, obedecendo à Resolução 466/12 do Conselho Nacional da Saúde.
} 
dados e é possível realizar adaptações necessárias eventualmente no roteiro préestruturado, como ocorreu em alguns momentos, a fim de esclarecer falas ou aprofundar alguns assuntos. O questionário foi aplicado para a obtenção de dados como grau de escolaridade, formação, idade e conhecimento a respeito de políticas públicas e documentos internacionais.

Os dados coletados nas entrevistas foram analisados conforme as três fases da análise de conteúdo (a pré-análise, a exploração do material e o tratamento dos resultados por meio de inferências e interpretações), que permitiram a transformação do texto bruto em representação do conteúdo via categorias.

Em um primeiro momento, apresentaremos neste artigo os principais fundamentos e documentos que orientam a educação em direitos humanos, por meio de citações de alguns pesquisadores e autores especialistas na área, a fim de contextualizar o estudo e possibilitar esclarecimentos acerca da temática enunciada. Após, levantaremos considerações a respeito da formação docente na perspectiva dos direitos humanos, mediante os dados obtidos por meio de questionário. No último tópico do texto discutiremos as categorias formadas a partir das falas do professorado acerca da educação em direitos humanos, revelando os principais significados atribuídos a essa forma de educar por aqueles que assumem uma função essencial no âmbito educacional: a mediação.

\section{EDUCAÇÃO EM DIREITOS HUMANOS: um caminho para a formação cidadã}

A educação em direitos humanos é um meio de desenvolvimento de sociedades onde os direitos humanos de todos e todas sejam respeitados, protegidos e cumpridos. No Brasil, as principais políticas públicas para a educação em direitos humanos são: o Programa Nacional de Direitos Humanos (PNDH) I, II e III, lançados, respectivamente, nos anos de 1996, 2002 e 2010; o Plano Nacional de Educação em Direitos Humanos (PNEDH), cuja primeira versão surgiu em 2003, foi revisada com ampla participação das universidades e da sociedade civil, esteve disponível para consulta em 2006 e foi atualizada no ano de 2013; e as Diretrizes Nacionais para a Educação em Direitos Humanos (DNEDH), lançadas em 2012. Já os principais documentos internacionais que orientam a educação em direitos humanos são os seguintes: a Declaração Universal dos Direitos Humanos (DUDH), 
de 1948; a Declaração e Programa de Ação de Viena, de 1993; e o Programa Mundial de Educação em Direitos Humanos (PMEDH), que foi dividido em três fases de Plano de Ação, com ações a serem implementadas de 2005 a 2019, cada fase com objetivos distintos.

Crítica ao modelo econômico neoliberal, Sacavino (2000) propõe três elementos à educação em direitos humanos (EDH). O primeiro deles, a chamada educação para o nunca mais, refere-se à necessidade do resgate histórico que culminou na Declaração Universal dos Direitos Humanos e em outros documentos importantes. Refere-se, também, à necessidade de cultivar a memória quanto aos acontecimentos marcados por violações de direitos. O segundo elemento é o desenvolvimento de metodologias voltadas à formação de sujeitos de direitos e atores sociais, ação referente ao exercício da cidadania plena. O terceiro elemento, por sua vez, trata da promoção do empoderamento, ou seja, o ato de possibilitar que os povos (principalmente os que historicamente tiveram menos poder na sociedade) sejam potencializados e passem a ser atores sociais. $O$ empoderamento favorece a organização dos grupos sociais minoritários para que mantenham participação ativa na sociedade civil. Trilha na mesma direção Candau (2005), acrescentando a visão integral dos direitos aos elementos anteriores.

Carbonari (2011), em consonância com o PNEDH, entende a educação em direitos humanos como um processo multidimensional e sistemático. A característica sistemática refere-se à articulação de momentos, estratégias e dimensões. Já a multidimensionalidade diz respeito à complexidade do que almeja a educação em direitos humanos. Assim, conforme o PNEDH, a educação em direitos humanos:

[...] Se traduz na perspectiva da "apreensão de conhecimentos historicamente construídos sobre direitos humanos", da "afirmação de valores, atitudes e práticas sociais", da "formação de uma consciência cidadã", do "desenvolvimento de processos metodológicos participativos", do "fortalecimento de práticas individuais e sociais". (CARBONARI, 2011, p. 121).

Silva (2010) também cita o PNEDH lançado em 2006, enfatizando que a concepção de educação em direitos humanos presente em tal documento vai além da mera contextualização e explicação das diversas variáveis inerentes à educação (aspectos culturais, sociais, políticos e econômicos). O documento, sobretudo, converge para uma pedagogia libertadora, na medida em que orienta a apreensão de conteúdos sobre a história, sobre as conquistas e violações de direitos, sobre os pactos, legislações e acordos. Além da apreensão de conteúdos, a autora destaca 
que a educação em direitos humanos, sob a ótica do PNEDH, deve trabalhar com valores e comportamentos éticos, além de pautar-se no conceito de cidadania ativa ${ }^{6}$, sem que se perca a ideia de vivência cotidiana daquilo que foi experienciado em sala de aula.

Educar na perspectiva dos direitos humanos é, conforme afirma Marinho (2012, p. 53):

[...] entender que os direitos humanos significam (devem significar) prática de vida em todas as áreas de convívio social dos sujeitos: na família, na escola, no trabalho, na comunidade, na igreja e no conjunto da sociedade. É trabalhar com a formação de hábitos, atitudes e valores com base nos princípios de respeito ao outro, de alteridade, de solidariedade, de justiça, em todos os níveis e modalidades de ensino.

De acordo com Viola, Barreira e Pires (2011), a educação em direitos humanos compreende a formação cidadã: reconhece os alunos e alunas como sujeitos de direitos que constroem sua autonomia. É, ademais, a construção da memória que historicamente é ocultada na tentativa de que não haja reivindicação de direitos por uma sociedade que pode ser (trans) formada criticamente por meio da educação.

Para Teixeira (2005), na mesma perspectiva, a educação em direitos humanos é entendida como uma educação para a democracia, isto é, como um processo que deve ser vivenciado de maneira que, em momento algum, o educando se esqueça de que é um cidadão. Deve contemplar a formação intelectual e a informação, a educação moral e a educação do comportamento, formando uma tríade que envolve tanto o conhecimento, quanto os aspectos político e axiológico.

Schilling (2005) também admite a educação em direitos humanos como essencial para a construção de uma cidadania democrática. Carvalho (2004), além de dispor da mesma concepção, acrescenta que a educação deve ser fundada no respeito aos princípios fundamentais da dignidade humana.

A educação em direitos humanos pode, pois, ser trabalhada a partir "[...] de um processo de sensibilização e formação da consciência crítica para e em direitos humanos, tendo como foco principal a formação de uma cultura democrática e participativa", e educar em direitos humanos é "[...] trabalhar para uma educação

\footnotetext{
${ }^{6} \mathrm{O}$ conceito de cidadania ativa e participativa é contraposto ao de cidadania formal e passiva, também chamada cidadania clássica. A cidadania passiva refere-se à cidadania outorgada pelo Estado, com a ideia moral de tutela. e de favor. Já o conceito de cidadania ativa refere-se à cidadania que institui o cidadão como portador de direitos e deveres, mas essencialmente como sujeito de direitos participante da esfera pública, e criador de novos direitos para abrir espaços de participação política.
} 
para a cidadania, é pensar em pessoas conscientes de seu protagonismo, direitos e deveres - uma cidadã e um cidadão ativos e solidários." (AFFONSO; SEDREZ, 2011, p. 9-10).

Em face de tais considerações teóricas, resta esclarecer de que maneira a formação cidadã - na acepção de cidadania plena e ativa - pode ocorrer contribuindo para com o fortalecimento da democracia: formar sujeitos de direitos é o processo chave da formação cidadã. Do ponto de vista jurídico, conforme afirma Sacavino (2012), se entende o sujeito de direito como a pessoa ou grupo susceptível de direitos e obrigações. Isso significa que, juridicamente, se atribui a faculdade de adquirir e de exercer direitos, e de assumir e cumprir obrigações. Diante dessa concepção, e tendo presente o texto do primeiro artigo da DUDH, ou seja, a afirmação de que todos os seres humanos nascem livres e iguais em dignidade e direitos, podemos concluir que todas as pessoas são sujeitos de direitos.

Contudo, essa concepção não é suficiente em contextos sociais excludentes como o do Brasil e da maioria dos países da América Latina, onde os direitos, no senso comum, muitas vezes são associados como válidos só às classes dominantes, restando à classe trabalhadora concessões feitas pelo Estado. Afirmar que todas as pessoas são sujeitos de direitos pelo simples fato de serem humanos implica, portanto, em quatro movimentos a serem desenvolvidos no processo educativo, segundo Candau et al. (2013).

O primeiro movimento supõe saber/conhecer os direitos, isto é, supõe conhecer a dimensão histórico-crítica da conquista de direitos, bem como conhecer declarações e documentos. O segundo movimento implica no desenvolvimento de uma autoestima positiva, aceitar-se como é, assumir-se em sua individualidade e reconhecer-se como ator social, além de sujeito de direitos. O terceiro movimento refere-se à promoção da capacidade argumentativa, para que os cidadãos e cidadãs saibam defender os próprios direitos e os direitos do outro. O quarto e último movimento diz respeito a ser um cidadão ativo e participativo, aquele que participa com intensidade da política nacional e internacional, e está ciente de que tem poder nelas.

Em suma, utilizamos a citação de Fortes (2010, p. 9):

A Educação em Direitos Humanos é compreendida como um processo sistemático e multidimensional que orienta a formação de sujeitos de direitos, articulando várias dimensões, como a apreensão de conhecimentos sobre Direitos Humanos; a afirmação de valores, atitudes e práticas que 
expressam uma cultura de Direitos Humanos; a afirmação de uma consciência cidadã; o desenvolvimento de processos metodológicos participativos; e o fortalecimento de práticas individuais e sociais que gerem ações e instrumentos em favor da promoção e defesa dos Direitos Humanos.

Podemos dizer, portanto, que a EDH luta pela emergência de uma nova sociedade, pautada em uma cultura de direitos humanos, que seja fortemente democrática, onde os cidadãos e cidadãs sejam ativos(as), conscientes de seus direitos e do processo histórico que permitiu a consolidação desses direitos. Uma sociedade em que os seres humanos gozem plenamente das condições de dignidade humana e sejam capazes de reconhecer a dignidade humana do outro. Nesse contexto, a liberdade, a igualdade, o reconhecimento da diferença e a solidariedade são premissas fundamentais que orientam outros valores necessários à condição de vida digna e à boa convivência da humanidade.

\section{PERFIL DO PROFESSORADO: CONHECIMENTOS E FORMAÇÃO DOCENTE}

O tratamento dos dados coletados em entrevista por meio de inferências e interpretações - terceira fase da análise de conteúdo - é um processo complexo que precisa considerar todos os dados obtidos no decorrer da pesquisa. Portanto, anteriormente à apresentação das categorias formadas a partir das falas do professorado acerca da educação em direitos humanos, apresentamos considerações a respeito dos dados coletados mediante questionário. É importante ressaltar que tais dados foram essenciais para o levantamento de conclusões sobre o estudo.

Apuramos qual o conhecimento do professor e das professoras entrevistadas acerca de documentos nacionais e internacionais que norteiam a educação em direitos humanos, na busca pela composição de um quadro sobre a formação dos sujeitos da pesquisa. As respostas foram sistematizadas no gráfico a seguir: 
Gráfico 1 - Conhecimento dos professores acerca de documentos nacionais e internacionais que orientam a educação em direitos humanos

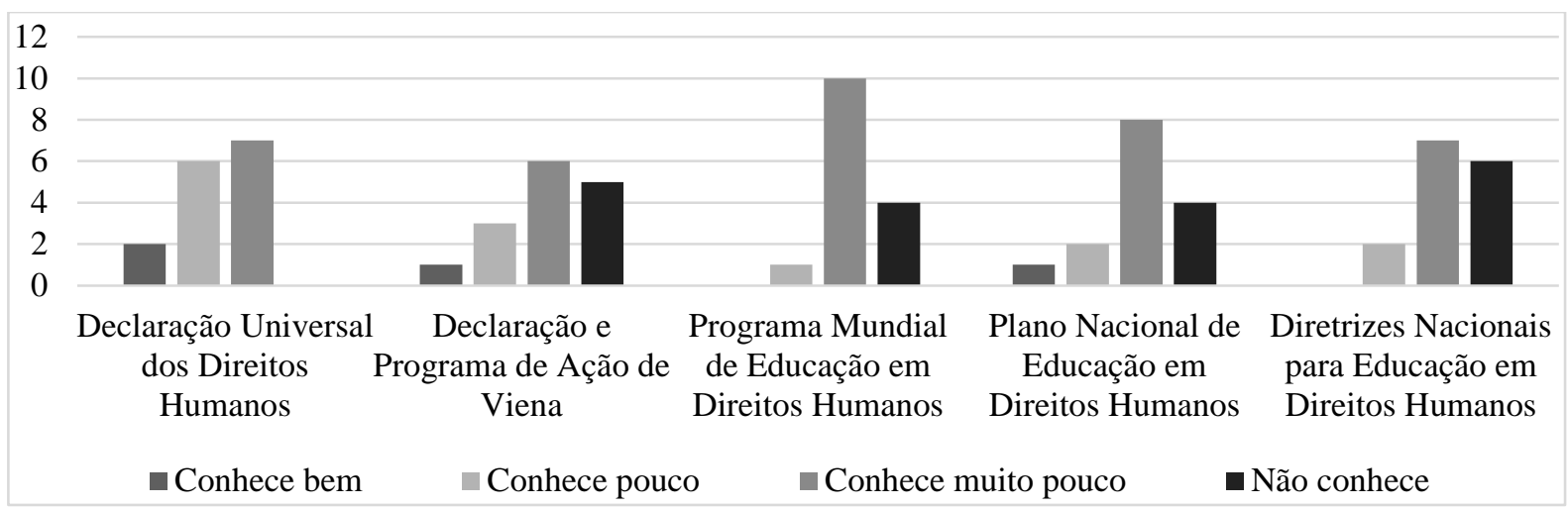

Fonte: Dados das autoras.

Como é possível observar, a maioria das respostas foram relacionadas nos campos "conhece muito pouco" e "não conhece", campos esses que revelam a inconsistência da base de conhecimentos desses professores para que um trabalho com os direitos humanos possa acontecer em âmbito escolar, mesmo em se tratando de um trabalho não sistematizado.

Cabe ressaltar que tais profissionais são servidores municipais da cidade de Marília-SP, que possui um contexto propício ao conhecimento de documentos mais básicos, como a Declaração Universal dos Direitos Humanos (DUDH), de 1948, por exemplo. Além de possuir uma política pública de direitos humanos ${ }^{7}$, a cidade conta com um Núcleo de Direitos Humanos cuja atuação é voltada diretamente à sociedade civil, não se restringindo, portanto, ao meio acadêmico. Esses dados apontam, pois, para uma outra problemática: se nem mesmo na referida cidade onde há pessoas engajadas com os direitos humanos, há discussão periódica sobre direitos humanos em eventos promovidos pelo Núcleo, e há projetos de extensão universitária sobre direitos humanos em algumas escolas públicas - documentos essenciais como a DUDH e a Declaração de Viena são conhecidos, como é a realidade de tantas outras cidades brasileiras?

Somam-se a esses dados, outros diretamente voltados à formação na perspectiva dos direitos humanos:

\footnotetext{
${ }^{7}$ A cidade de Marília possui o Programa Municipal de Direitos Humanos, elaborado em 2004 pelo Núcleo de Direitos Humanos e Cidadania de Marília, juntamente com a sociedade civil e representantes públicos. O Programa conta com nove áreas temáticas, dentre elas a educação. $\mathrm{O}$ programa foi revisado e atualizado no ano de 2017.
} 
Gráfico 2 - Recebimento de formação em Direitos Humanos na educação formal e/ou formação continuada

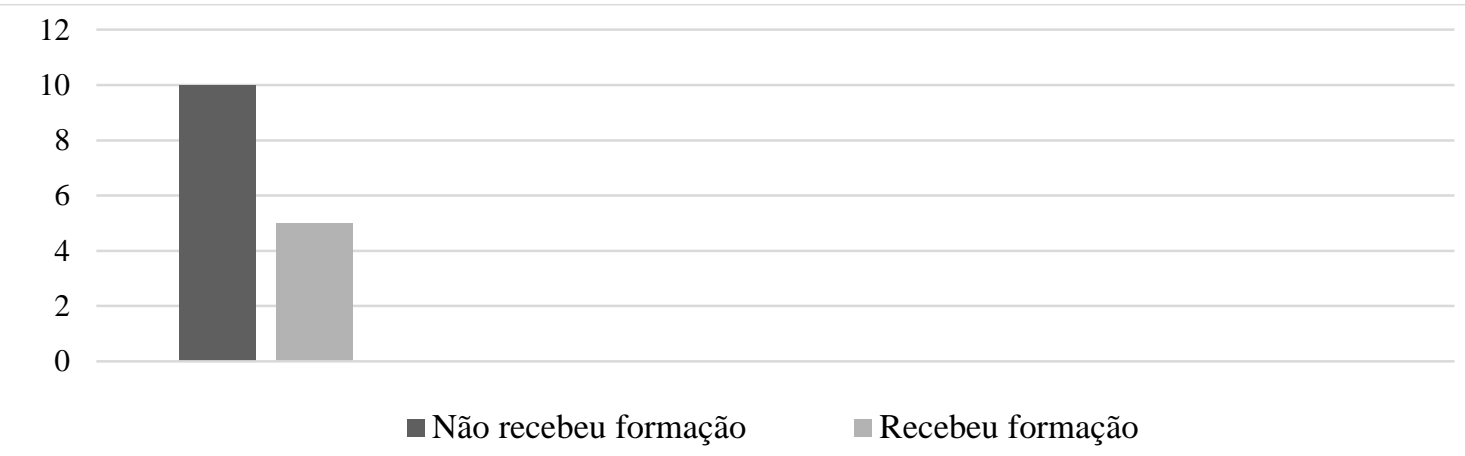

Fonte: Dados das autoras.

Os cinco sujeitos da pesquisa que alegaram ter recebido formação em direitos humanos durante a Educação Básica, Superior e/ou educação continuada, disseram não conhecer o contexto histórico que permitiu a consolidação dos direitos humanos, tampouco seus mecanismos de defesa. As falas demonstraram que esses professores tiveram contato com poucas ações isoladas que não foram significativas para que houvesse ao menos sensibilização quanto ao principal sentido dos direitos humanos: "o reconhecimento da dignidade inerente a todos os membros da família humana e de seus direitos iguais e inalienáveis [...]" (ONU, 1948, p. 1). Esta afirmação fica muito clara nos seguintes dizeres: "eu penso que direitos humanos é quando você tem um direito dentro de um contexto, e é necessário refletir mesmo se você tem esse direito humano" (E7, 2016). Desse ponto de vista, depreende-se a ideia de concessão de direitos (humanos) apenas a algumas pessoas, segundo um critério de merecimento.

Como destaca Carvalho (2007, p. 482, grifos do autor):

Ações pontuais tendem a ser largamente insuficientes se o que se pretende, mais do que difundir informações, é o cultivo de valores que se traduzam num modo de vida, ou seja, uma formação voltada para uma ação éticopolítica identificada com os direitos humanos. [...] A solidez de uma formação em valores não resulta do esforço isolado e pontual de um professor determinado num evento específico, mas de uma ação conjunta e contínua da instituição escolar como um todo.

Assim, o currículo indispensável para se formar o educador e a educadora, bem como as metodologias e práticas envolvidas na efetivação de uma cultura de direitos humanos não deveriam se restringir a uma mera disposição de discussões isoladas em um tempo e espaço escolares, mas, ao contrário, o currículo, na 
perspectiva da educação em direitos humanos, configura-se enquanto "um lugar em que, ativamente, em meio a tensões, se produz e se reproduz a cultura. Currículo refere-se, portanto, à criação, recriação, contestação e transgressão", conforme as palavras de Moreira e Candau (2008, p. 28). O currículo faz parte da política cultural da educação que considera, de maneira integrada, aspectos econômicos, valores, raça, gênero, visões de família, relações entre diferença e identidade, entre outros fatores que permitem uma formação com pluralidade de ideias, problematizadora e dialógica. Compartilham dessas ideias Apple (2000) e Dias e Porto (2010).

Para além dos dados sobre a formação em direitos humanos, é válido mencionar dados que apontam para a formação docente como um todo, destacando características que dificultam o alcance de uma educação plena quanto aos preceitos dos direitos humanos. Para isso, discutimos, a seguir, a forma atual com que a Educação Superior é abordada no Plano Nacional de Educação em Direitos Humanos (PNEDH).

O PNEDH destaca a concepção e os princípios da educação em direitos humanos na Educação Superior, e prevê um conjunto de vinte e uma ações programáticas, destacando a indissociabilidade entre ensino, pesquisa e extensão. Assim expressa o documento:

As atribuições constitucionais da universidade nas áreas de ensino,
pesquisa e extensão delineiam sua missão de ordem educacional, social e
institucional. A produção do conhecimento é o motor do desenvolvimento
científico e tecnológico e de um compromisso com o futuro da sociedade
brasileira, tendo em vista a promoção do desenvolvimento, da justiça social,
da democracia, da cidadania e da paz. (BRASIL, 2013, p. 29-30).

Nesse sentido, o tripé ensino-pesquisa-extensão possibilita que as universidades contribuam não só no que diz respeito à formação profissional, mas também no que concerne ao desenvolvimento da capacidade crítica, e de uma postura democrática e emancipadora.

No entanto, de acordo com o Decreto n 5. 773, de 9 de maio de 2006 (BRASIL, 2006), que dispõe sobre o exercício das funções de regulação, supervisão e avaliação de Instituições de Ensino Superior (IES) e cursos superiores de graduação, as IES são credenciadas em três modalidades, que se diferenciam de acordo com sua organização e respectivas prerrogativas acadêmicas, a saber: faculdades, centros universitários e universidades. A rigorosidade quanto à concentração dos três eixos de atividades acadêmicas (ensino, pesquisa e extensão) e 
as exigências de alcance de padrões de qualidade e de corpo docente mais qualificado destinam-se apenas às universidades.

Dentre os 15 sujeitos da pesquisa, 10 frequentaram uma universidade, enquanto 3 frequentaram uma faculdade e 2 não possuem Ensino Superior. Dessa forma, nem todos os sujeitos tiveram adequado acesso à pesquisa e à extensão, assim como tantos outros estudantes brasileiros não possuem acesso. Essa situação leva-nos a pensar sobre o alcance das discussões em torno dos direitos humanos nas IES brasileiras, para que haja um trabalho efetivo na perspectiva que aponta o Plano Nacional de Educação em Direitos Humanos.

Outros dados que chamam a atenção e auxiliam a compor o contexto geral dessas professoras e desse professor, relacionam-se a fatores socioeconômicos: a maioria das entrevistadas relacionou a escolha da docência à dificuldade financeira, mencionando que, caso fosse possível, exerceriam outra profissão, como demonstra a seguinte fala: "antes de ser professora eu quis ser médica pediatra, mas não deu certo, pela dificuldade financeira, e aí eu resolvi fazer magistério." (E9, 2016).

Assim, considerando-se todos os dados que permitiram a composição de um perfil dos profissionais entrevistados, embora o objetivo geral da pesquisa relatada neste texto tenha se centrado nas concepções de professores de educação infantil e nas políticas públicas de educação em direitos humanos, uma outra categoria emergiu das falas dos professores e consideramos importante incorporá-la aos objetivos específicos desta pesquisa: a formação docente ${ }^{8}$. Fica nítida a falta de disposição para o exercício do magistério, além da frustação com relação à escolha do curso de Pedagogia; a falta de contato com ações significativas no que diz respeito aos direitos humanos durante os anos de formação; e, somadas a isso, estão as implicações das recentes políticas públicas de educação em direitos humanos quanto às especificidades das IES, e o papel das IES frente às demandas dessas políticas.

$\mathrm{Na}$ última fase da entrevista, os entrevistados tiveram oportunidade de se expressar livremente, com comentários, acréscimos ou ratificações. É importante destacar que as únicas professoras que quiseram falar proferiram as seguintes palavras: "eu acho que em relação a essas questões dos direitos humanos seria

\footnotetext{
${ }^{8}$ É imprescindível registrar que tal categoria emergiu como objetivo específico porque os resultados desse estudo são decorrentes da formação docente. No entanto, limitamo-nos, neste trabalho, a destacar a necessidade de que novas pesquisas tomem a formação docente como objeto de investigação.
} 
legal os professores terem uma formação, por exemplo na faculdade, eu não me lembro de ter visto isso, então seria legal." $(E 5,2016)$.

Eu gostaria mesmo que a gente soubesse mais dos direitos, recebesse formação, até para passar para as crianças, que é importante para o futuro deles, para cada um poder se defender melhor, poder se impor, se colocar melhor. É para sempre, é para a vida. $(E 9,2016)$.

É imprescindível, pois, que a formação docente e as condições profissionais dos professores sejam levadas em consideração no debate sobre a educação em direitos humanos, não só por outras pesquisas acadêmicas, mas, sobretudo, pelas políticas públicas e pelos documentos internacionais cujo conteúdo mencione o trabalho com os direitos humanos no campo educacional, para que, de fato, a educação em direitos humanos cumpra com seu objetivo de consolidação de uma cultura pautada nos princípios dos direitos humanos.

\section{A CONSTITUIÇÃO DE CATEGORIAS: discussões sobre os significados} atribuídos por professores à educação em direitos humanos

Os dados coletados mediante entrevista foram submetidos a um processo denominado codificação textual na análise de conteúdo, processo este que compreende três escolhas: o recorte, a enumeração e a categorização. Os procedimentos de recorte e enumeração conduzem o pesquisador na escolha e tratamento de índices, e na organização dos seus devidos indicadores. Os indicadores sintetizam a mensagem, auxiliando na posterior categorização.

A categorização, por sua vez, "é uma operação de classificação de elementos constitutivos de um conjunto, por diferenciação e, seguidamente, por reagrupamento segundo o gênero (analogia), com os critérios previamente definidos." (BARDIN, 2002, p. 117). Enquanto última etapa do processo de codificação, a categorização permite a visualização organizada e simplificada de todos os dados brutos submetidos à análise. No caso deste estudo, foi possível formar quatro grandes categorias: a) Educação em direitos humanos como formação cidadã na acepção clássica; b) Educação em direitos humanos relacionada a valores; c) Educação em direitos humanos vista sob uma perspectiva pejorativa; d) Educação em direitos humanos como meio de busca àquilo que beneficia o ser humano.

A principal categoria formada a partir da fala dos professores é a que diz respeito à concepção de educação em direitos humanos como formação cidadã na 
acepção clássica ${ }^{9}$. A condição de ser cidadão, nesta perspectiva, está ligada a ser sujeito de direitos e deveres e a uma concepção reducionista de cidadania (MARSHALL, 1967). Como coloca Albuquerque (2011, p. 129), nessa visão, "[...] o indivíduo é sujeito de direitos e deveres e é considerado quando cumpre seus deveres; por isso goza dos direitos". Assim, produz-se uma ideia funcionalista, na qual cada direito corresponde a uma obrigação normativa presente na legislação. As seguintes palavras sintetizam os discursos dessa categoria:

[...] uma educação voltada para o desenvolvimento do cidadão faz com que ele reconheça os direitos e deveres, porque é muito isso, é uma via de mão dupla, a gente não pode só lutar pelos nossos direitos não, a gente tem que saber que tem muitas obrigações também. (E11, 2016).

Falas que vão ao encontro de uma visão passiva de cidadania também apareceram nos diferentes discursos que se enquadram nessa categoria, como a seguinte: "quem tem que mudar a sociedade é quem está lá em cima [...], porque a minha ideia aqui, a gente não pensa igual. Então eu vou brigar?" (E6, 2016). O significado de cidadania como uma atitude passiva está em delegar unicamente aos representantes políticos a responsabilidade de luta, ou seja, cabe somente aos eleitos por voto periódico a tarefa de exigir do Estado a implementação de políticas públicas, a criação de estratégias e investimento adequados em justiça social.

Embora seja necessário destacar o sentido sociológico de cidadania como instituição político-jurídica, é preciso que se acrescente a ele a efetividade de participação dos sujeitos de direitos para a configuração de uma vertente ativa de cidadania. O conceito de cidadania frente ao Estado Democrático de Direito precisa, portanto, ser entendido considerando-se o direito de participação do cidadão e da cidadã no poder, e como característica da democracia que se configura pela efetiva atuação política desses cidadãos na comunidade. Implica na condição do sujeito como membro de comunidade política baseada no sufrágio universal, mas, sobretudo, na concretização da cidadania plena e coletiva.

Nas palavras de Covre (1993, p. 10), "as pessoas tendem a pensar a cidadania apenas em termos dos direitos a receber, negligenciando o fato de que

\footnotetext{
${ }^{9}$ Por meio do processo de enumeração dos índices na análise de conteúdo foi possível verificar que tal categoria é a mais significativa porque os índices "direitos" e "deveres/obrigações" - que serviram de base para a constituição da categoria - foram os mais citados em todo o conteúdo analítico. Mencionadas dezessete vezes, em diferentes falas, e de diferentes pessoas solicitadas a dizerem o que entendem sobre a educação em direitos humanos, as palavras "direitos" e "deveres/obrigações" representam $19,3 \%$ dos índices.
} 
elas próprias podem ser agentes da existência desses direitos". Assim, acabam por ressaltar os deveres que lhes cabem de acordo com a lei, omitindo-se no sentido de serem, também, de alguma forma, parte do governo. "Em vez de meros receptores, são acima de tudo sujeitos daquilo que podem conquistar". Em verdade, pois, quando os discursos enfatizam o dever do cidadão e da cidadã na concepção de cidadania, este deveria estar relacionado não à obrigatoriedade normativa, mas à luta pela dignidade da pessoa humana e pela justiça social.

As falas que originaram a primeira categoria em discussão revelam uma concepção contratualista de educação em direitos humanos: é preciso educar para que a criança conheça seus direitos e regras de conduta para que mantenham obediência à lei. Se, então, cumprirem com todas suas obrigações, poderão usufruir de seus direitos.

A partir de tais considerações, problematizamos a concepção de educação em direitos humanos como formação cidadã na acepção clássica, pois a construção da democracia, em sua acepção material e enquanto regime político que está em consonância com uma cultura de direitos humanos, só é possível a partir do exercício da cidadania que caminha no mesmo sentido material, ativo e pleno. Se a formação para a cidadania não contemplar, então, a formação de sujeitos de direitos e, ao contrário, basear-se na visão liberal de correspondência entre direitos e obrigações, dificilmente mudanças no atual quadro político e social serão possíveis.

Outra categoria formada a partir dos discursos sintetiza a relação que o professorado estabeleceu entre a educação em direitos humanos e princípios éticos. É importante dar início à análise dessa categoria ressaltando que a concepção de educação infantil dos sujeitos da pesquisa está atrelada a dois processos que, segundo eles, são distintos: o primeiro diz respeito ao ensino, ou seja, aos conhecimentos científicos de diferentes naturezas que devem ser transmitidos às crianças; o segundo refere-se à educação, esta concebida como promotora de princípios éticos, valores e virtudes. Enquanto o primeiro processo é bem aceito na escola da infância, o segundo é rejeitado com o argumento de que educar é papel das famílias, e não da escola, como demonstra a fala do sujeito E9 (2016): "na verdade, a educação não é, para mim, a parte da família, que ela tem que educar, por limites. Educação mesmo dentro da escola, é da parte de ensinar, alfabetizar, não de educar a criança". 
$\mathrm{Na}$ ideia da maioria dos entrevistados, a escola deveria meramente transmitir conhecimentos científicos sem lidar com princípios axiológicos, já que esses deveriam "vir de casa". Porém, como nos dias de hoje a criança passa parte preponderante de seu tempo na escola, a demanda de trabalho dos profissionais da educação, segundo as professoras e o professor, aumentou, e esses precisam agora educar, para além de ensinar.

Ao frisarem uma dicotomia entre os termos ensino e educação, os entrevistados demonstraram estar aquém dos objetivos da educação infantil incorporados por discursos oficiais. De acordo, por exemplo, com as Diretrizes Curriculares Nacionais para a Educação Infantil (BRASIL, 2009), a escola de educação infantil é lócus privilegiado para o trabalho com princípios éticos, políticos e estéticos, e deve cumprir com sua função sociopolítica e pedagógica, oferecendo condições para que as crianças usufruam de seus direitos civis, humanos e sociais, dentre outras responsabilidades.

Sobretudo, ao tomar os termos ensinar e educar como processos distintos e, ao demonstrarem a rejeição ao sentido que para eles possui o educar, os professores revelaram uma postura de resistência diante da educação em direitos humanos, pois a educação ética é parte constituinte de suas premissas. Dessa forma, o professorado de fato proferiu concepções que vão ao encontro da literatura e das políticas públicas para a educação em direitos humanos, mas a aceitação da EDH por parte do professorado é questionável. Se não aceitam o "educar", então não aceitam a inserção dos direitos humanos de forma ampla na educação.

Como afirma Arendt (1978, p. 239), o educador é representante de um mundo pelo qual deve assumir responsabilidade, e "qualquer pessoa que se recuse a assumir a responsabilidade coletiva pelo mundo não deveria ter crianças, e [...] tomar parte em sua educação". Em outras palavras, todos os seres humanos possuem responsabilidades em relação à vida social, à convivência pacífica e ao meio ambiente. Tais responsabilidade são, pois, coletivas e sua abordagem passa, da mesma forma, por um esforço coletivo, e não, ao contrário, pelo ensino isolado de conhecimentos científicos.

Considera-se, ainda, que até mesmo o termo ensino, que foi relacionado diretamente à ciência, quando não é pautado em princípios éticos e democráticos, transforma-se em dogma e descaracteriza o verdadeiro sentido de ensinar 
(POPPER, 1986). Assim, o cultivo de valores não se desvincula da própria ideia de ciência. Ao contrário, "[...] um ensino que o incorpore respeita não só um ideal caro à ciência, como um procedimento fundamental à democracia e à própria instituição escolar." (CARVALHO, 2004, p. 100).

Fica evidente, diante dos discursos que originaram esta categoria, a necessidade de formação continuada sistemática e voltada à sensibilização dos profissionais da educação. Afinal, embora a ideia que os sujeitos da pesquisa possuem esteja de acordo com a produção de conhecimento no âmbito desse campo de estudos denominado educação em direitos humanos, a concepção não pressupõe a prática no cotidiano escolar.

Outros discursos, que permitiram a constituição da terceira categoria aqui tratada, revelam uma visão pejorativa sobre os direitos humanos e, consequentemente, sobre a educação em direitos humanos, como demonstra a fala a seguir: "direitos humanos eu falo que hoje são coisas bem distorcidas [...]. Você vê aí o contexto, os direitos humanos defendendo um rapaz que não tem uma boa índole, então, até que ponto essa pessoa tem direito?" (E7, 2016).

Procedemos à análise, pois, procurando compreender, a partir de elementos histórico-sociais, como se deu a má associação entre os direitos humanos e ideias ruins, processo que constituiu uma perspectiva que ainda hoje faz parte do pensamento de tantos brasileiros e brasileiras.

Mesmo sendo a violência e a criminalidade problemas constantes, que assumem características singulares de acordo com o contexto e com as formas em que se manifestam, chama a atenção, por sua importância política, o cenário de embate entre a realidade violenta, o processo de redemocratização, e os discursos sobre direitos humanos da década de 1980 no Brasil. De reivindicação democrática central no processo da chamada abertura política, os direitos humanos foram transformados, no contexto de discussões sobre a criminalidade, em privilégios de bandidos a serem combatidos por aqueles que se consideravam "homens de bem". A fim de se analisar como essa transformação foi possível, utilizamos os estudos de Caldeira (1991), Benevides (2007) e Viola (2010).

Faz-se necessário, primeiramente, compreender que a noção de direitos foi primordial no debate político do período posterior à ditadura civil-militar, e adquiriu significados distintos, à medida em que os direitos eram associados a diferentes 
práticas sociais. Assim, a partir de meados dos anos 1970, e sobretudo durante os anos 1980, houve uma expansão dos direitos políticos e sociais, com a ênfase nos direitos humanos, já que a situação envolvia a tortura e a prisão política, a atuação de movimentos sociais, e lutas pelos direitos à saúde, à moradia, ao transporte, à habitação, à iluminação pública, ao uso de creches, entre outros.

Em virtude dessas características de defesa das minorias, na década de 1980 as noções de direitos e de direitos humanos confundiram-se, e passaram a ser tratadas como expressões sinônimas. No entanto, a associação, nesse mesmo período, dos direitos humanos a direitos que defendem apenas delinquentes, revelou, por um lado, os significados conflitantes e os limites postos à expansão dos direitos na sociedade brasileira e, por outro lado, revelou o impasse político a que foram levados os defensores dos direitos humanos em meio a esse cenário.

Ocorre que o país enfrentava o aumento da criminalidade e da violência, e, com isso, as penitenciárias iam ficando cada vez mais cheias e em condições desumanas. Então, ao passo que surgiam debates sobre a proteção dos direitos humanos dos prisioneiros comuns $^{10}$, surgiam, também, argumentações e manifestações de opositores à defesa dos direitos humanos. De acordo com Caldeira (1991), a organização argumentativa dos defensores dos direitos humanos voltava-se para os direitos coletivos e especialmente para a lógica estritamente política de oposição ao regime militar, ou seja, para a defesa dos prisioneiros políticos. Porém, tais referências argumentativas não podiam ser facilmente transpostas para o caso dos prisioneiros comuns, ocasionando uma certa fragilidade no convencimento da população, movida pelo medo e pela insegurança, principalmente em meio à discussão promovida pelos opositores.

Se, pois, os prisioneiros não podiam naquele momento serem integralmente respeitados como cidadãos ${ }^{11}$, que fossem respeitados por serem humanos. Era essencial que se resgatasse nas argumentações o real sentido dos direitos humanos: o reconhecimento da dignidade humana, que incide no próprio direito à vida (ONU, 1948).

\footnotetext{
${ }^{10}$ A expressão "prisioneiros comuns" foi utilizada para referir-se àquelas pessoas que de fato haviam cometido um crime e não eram prisioneiros políticos.

${ }^{11}$ A campanha foi promovida em defesa de pessoas que não eram militantes políticos, cujo "crime" era discordar dos donos do poder. Tratava-se de pessoas que tinham de fato cometido algum tipo de crime e, portanto, naquele momento, tinham sua cidadania restringida. Nesse caso, ou seja, de pessoas com culpa comprovada e cumprindo pena, a situação criminosa não era questionável, e a condição de cidadania não era plena.
} 
Ainda procurando compreender a associação dos direitos humanos à defesa unicamente de criminosos, destacamos os meios de comunicação de massa, os quais, no contexto de debate do período pós regime militar, tiveram um papel importante na articulação da campanha contra os direitos humanos. Não obstante houvesse a variação na abordagem de cada assunto relacionado aos direitos humanos por parte da mídia - desde o uso de linguagem jurídica até a ênfase em notícias de corpos mutilados, por exemplo -, em todos os contextos exagerava-se na sensação de insegurança e violência relacionadas à criminalidade.

Viola (2010) também salienta o papel da grande mídia nessa conjuntura histórica, não só no que diz respeito à associação dos direitos humanos à defesa de criminosos, mas, também, no que diz respeito à identificação dos próprios defensores de direitos humanos como bandidos, identificação essa que ainda persiste no senso comum da população, conforme também aponta Benevides (2007).

Julgamos que todos esses fatos históricos trouxeram ideias pejorativas que persistem no pensamento de muitos brasileiros. Percebe-se, ainda, uma certa incredulidade quanto aos direitos humanos, pois, embora muitos deles tenham sido incorporados na legislação brasileira, o quadro de violação é diário. Diante de tais considerações, citamos Rabenhorst, para quem: "nossas ações e omissões têm consequências na vida dos outros seres humanos" (2008, p. 59). Sendo assim, por mais que muitos brasileiros - dentre eles profissionais da educação - tenham uma ideia negativa sobre os direitos humanos, a (des)construção e vivência de seu conceito e sentido é sempre necessária, inclusive por meio da educação, seja ela formal, informal, ou enquanto formação continuada.

As falas dos professores que permitiram a constituição da quarta categoria, qual seja, a educação em direitos humanos como meio de busca àquilo que beneficia o ser humano, apontam para a justificação moral dos direitos humanos, na medida em que resgatam a ideia de busca àquilo que faz bem e que, por consequência, permite a satisfação de necessidades básicas. Duas das professoras entrevistadas assim se expressaram: "eu acho que educação em direitos humanos é quando você ensina a criança a buscar aquilo que faz bem." (E3, 2016). "Direitos humanos seria o acesso a tudo o que faz bem, tudo o que pode permitir o bem-estar de um ser humano." (E8, 2016). 
De acordo com Rabenhorst (2008, p. 51), a ideia de direitos pode ser justificada tanto a partir de uma ordem jurídica, quanto a partir de uma ordem moral, dando origem, portanto, a duas classes de direitos: os direitos legais e os direitos morais. Os direitos humanos, concebidos como o "[...] conjunto de faculdades e instituições que buscam tornar possíveis as condições básicas de existência e coexistência dos seres humanos", são, simultaneamente, direitos legais e direitos morais $^{12}$. A justificação dos direitos humanos, em virtude desta dupla classificação, acontece por elementos jurídicos, e por uma natureza moral, sendo que esta última se apoia, juntamente com o argumento da dignidade humana, na tentativa de identificação de necessidades básicas comuns a todos os seres humanos.

Justamente por serem fundamentadas pelo pressuposto de igualdade universal da pessoa humana, as necessidades básicas justificam a atribuição de direitos morais. Como afirma Rabenhorst (2008, p. 59), "afinal, os seres humanos não são autossuficientes, mas necessitam de ajuda para a consecução de uma vida digna e autônoma". A partir desse ponto de vista, facilmente a meritocracia, proveniente do pensamento liberal, apresenta-se como uma falácia: "os seres humanos não podem exercer ações livres, perseguir fins ou optar por um determinado curso de atuação se determinadas pré-condições não são respeitadas." (p. 59). Nesse sentido, para que homens e mulheres possam guiar suas vidas, é preciso que necessidades básicas sejam devidamente satisfeitas.

Atender às necessidades básicas dos seres humanos significa proteger e promover ações que garantam a vida e a autonomia. Se a compreensão dos direitos humanos perpassa pelo entendimento sobre o que significam as necessidades humanas básicas, as biológicas e as sociais, então essa compreensão volta-se para a satisfação humana, considerando o ser humano em sua integralidade. É preciso, pois, ao analisar tais questões, lembrar que a noção de integralidade ainda não é plenamente cumprida em muitos países, especialmente no Brasil - um país que carrega a marca da injustiça social, da pobreza e da desigualdade.

Pode-se dizer que as concepções do professorado que se encaixam nessa quarta categoria são as concepções que mais se aproximam das bases presentes nos documentos nacionais que orientam a educação em direitos humanos, os quais

\footnotetext{
12 Direitos legais são demandas reconhecidas por uma lei positiva (nacional ou internacional), reivindicáveis diretamente ao Estado e suas instituições. Direitos morais, em contrapartida, são pretensões que os indivíduos possuem independentemente da existência de uma lei que os explicite.
} 
reconhecem a dignidade humana e o bem-estar humano como princípios primordiais.

Importa, por fim, compreender que os direitos humanos não são meras diretrizes criadas para toda a população mundial, mas existem para assegurar condições de vida dignas. Eis, contudo, o grande desafio da contemporaneidade: não é possível pensar em um mundo em que todos vivam de maneira digna e justa sem que se estabeleça algum critério de igualdade nos diversos âmbitos da sociedade, mas, mesmo que já tenhamos caminhado nessa direção, "o que falta, e não é pouco, é identificar a política [e a organização econômica] capaz de realizar essa igualdade." (TOSI, 2008, p. 81).

\section{CONSIDERAÇÕES FINAIS}

Ao finalizarmos este artigo queremos registrar, sobretudo, que nossa intenção ao desenvolvermos tal pesquisa com os docentes não foi realizar uma análise focada na pessoa, em sua individualidade, pois muitos fatores sociais, históricos e culturais interferem nas concepções que a pessoa constitui. Em outras palavras, reconhecemos que todas essas professoras e esse professor que foram entrevistados estão inseridos em um meio social e a vivência em sociedade influenciou suas percepções, significados e opiniões acerca da temática.

Nessa perspectiva, concluímos que os resultados desta pesquisa apontam para uma grande questão: a formação docente. Foi possível inferir que o processo de formação desses profissionais não contemplou os principais objetivos da educação em direitos humanos. O quadro que emerge das falas desses profissionais aponta que as ideias acerca dos direitos humanos que possuem são as do senso comum, distanciam-se de qualquer ideia formal, e realçam o quanto 0 professorado necessita de formação continuada.

Cabe mencionar que a educação em direitos humanos representa, nos dias de hoje, uma das demandas para a formação docente, tanto inicial quanto continuada, e aparece como um dos objetivos a serem cumpridos pelas instituições de ensino superior. Citamos as Diretrizes Curriculares Nacionais para a Formação Inicial e Continuada dos Profissionais do Magistério da Educação Básica, cujo texto explicita: "[...] a educação em direitos humanos é uma necessidade estratégica na 
formação dos profissionais do magistério e na ação educativa em consonância com as Diretrizes Nacionais para a Educação em Direitos Humanos." (BRASIL, 2015).

Esperamos, portanto, que esta pesquisa possa despertar o interesse em outros pesquisadores quanto à investigação sobre a presença da educação em direitos humanos nos cursos de Pedagogia, assim como determinam as políticas públicas atuais. Afinal, são os professores formados nesses cursos os responsáveis pela difusão dos princípios dos direitos humanos na educação básica, e só é possível ensinar aquilo que se conhece.

Por fim, para encerrar a discussão acerca da educação em direitos humanos tendo em vista a escola como lócus privilegiado de trabalho, deixamos as palavras de Gadotti, com as quais concordamos (1984, p. 63): "a educação não é certamente, alavanca da transformação social. Porém, se ela não pode fazer a transformação, essa transformação não se efetivará [...] sem ela". Assim, a viabilidade de transformações não depende exclusivamente da educação escolar, visto que, sobretudo, está atrelada a fatores econômicos amplos, mas, a escola, enquanto importante instituição social, necessita também comprometer-se com os interesses e bem-estar da sociedade. 


\section{REFERÊNCIAS}

AFFONSO, D.; SEDREZ, M. L. da C. Introdução: Educar em direitos humanos: Um desafio. In: VIOLA, S. E. A.; ALBUQUERQUE, M. Z de. (Org.). Fundamentos para Educação em Direitos Humanos. São Leopoldo: Sinodal/EST, 2011. p. 9-16.

ALBUQUERQUE, M. Z. de. Cidadania comunicativa: direitos humanos no espaço digital. In:

VIOLA, S. E. A.; ALBUQUERQUE, M. Z. (Org.). Fundamentos para Educação em Direitos Humanos. São Leopoldo: Sinodal, 2011. p. 128-142.

APPLE, M. W. Política cultural e educação. Tradução de Maria José do Amaral Ferreira.

São Paulo: Cortez, 2000.

ARENDT, H. Entre o passado e o futuro. São Paulo: Perspectiva, 1978.

BARDIN, L. Análise de conteúdo. Lisboa: Edições 70, 2002.

BENEVIDES, M. V. Direitos humanos: desafios para o século XXI. In: SILVEIRA, R. M. G. et al. Educação em Direitos Humanos: Fundamentos teórico-metodológicos. João Pessoa: Editora Universitária, 2007. p. 335-350.

BRASIL. Comitê Nacional de Educação em Direitos Humanos. Plano Nacional de Educação em Direitos Humanos. Brasília: Secretaria Especial dos Direitos Humanos, Ministério da Educação, Ministério da Justiça, UNESCO, 2013.

. Decreto n. 5.773, de 9 de maio de 2006. Dispõe sobre o exercício das funções de regulação, supervisão e avaliação de instituições de educação superior e cursos superiores de graduação e sequenciais no sistema federal de ensino. 2006. Disponível em:

$<$ http://portal.mec.gov.br/seed/arquivos/pdf/legislacao/decreton57731.pdf>. Acesso em: 31 jan. 2019.

. Parecer CNE/CP, no 2/2015. Discute as Diretrizes Curriculares Nacionais para a Formação Inicial e Continuada dos Profissionais do Magistério da Educação Básica. Brasília: Conselho Nacional da Educação, 2015.

Parecer n. 20, de 9 de dezembro de 2009. Revisa as Diretrizes Curriculares Nacionais para a Educação Infantil. Brasília: CNE/CEB, 2009.

CALDEIRA, T. P. do R. Direitos humanos ou "privilégios de bandidos"? Desventuras da democratização brasileira. Novos estudos, n. 30, jul. 1991. 
CANDAU, V. M. Educação em direitos humanos: principais desafios. Rio de Janeiro: 2005 (mimeo).

. et al. Educação em Direitos Humanos e formação de professores(as). 1 ed. São Paulo: Cortez, 2013.

CARBONARI, P. C. Educação em direitos humanos: por uma nova pedagogia. In: VIOLA, S. E. A.; ALBUQUERQUE, M. Z. (Org.). Fundamentos para educação em direitos humanos. São Leopoldo: Sinodal, 2011. p. 119-127.

CARVALHO, J. S. et al. Formação de professores e educação em direitos humanos e cidadania: dos conceitos às ações. In: CARVALHO, J. S. (Org.). Educação, cidadania e direitos humanos. Petrópolis: Vozes, 2004. p. 331-351.

. Uma ideia de formação continuada em educação e direitos humanos. In: SILVEIRA, R. M. G. et al. Educação em Direitos Humanos: Fundamentos teóricometodológicos. João Pessoa: Editora Universitária, 2007. p. 469-486.

COVRE, M. L. M. O que é cidadania. 2. ed. São Paulo: Brasiliense, 1993.

DIAS, A. A.; PORTO, R. C. C. A Pedagogia e a Educação em Direitos Humanos: subsídios para a inserção da temática da Educação em Direitos Humanos nos cursos de Pedagogia. In: FERREIRA, L. F. G.; ZENAIDE, M. N. T.; DIAS, A. A. (Org). Direitos Humanos na Educação Superior: Subsídios para a Educação em Direitos Humanos na Pedagogia. João Pessoa: Editora Universitária da UFPB, 2010. p. 2963.

FORTES, E. Apresentação. In: TAVARES, C.; SILVA, A. M. M. (Org.). Políticas e fundamentos da educação em direitos humanos. São Paulo: Cortez, 2010. p. 713.

FRANCO, M. L. P. B. Análise de conteúdo. 3. ed. Brasília, DF: Liber, 2008.

GADOTTI, M. Educação e Poder: Introdução à Pedagogia do Conflito. 5. ed. São

Paulo:

Cortez, 1984.

MARINHO, G. Educar em Direitos Humanos e Formar para a Cidadania no Ensino Fundamental. São Paulo: Cortez, 2012.

MARSHALL, T. H. Cidadania, classe social e status. Rio de Janeiro: Zahar, 1967.

MOREIRA, A. F.; CANDAU, V. M. In: BRASIL. Indagações sobre currículo.

Brasília:

Ministério da Educação, Secretaria da Educação Básica, 2008. p. 15-32.

ONU. Organização das Nações Unidas. Declaração Universal dos Direitos Humanos,

adotada e proclamada pela Resolução 217 A (III) da Assembleia Geral das Nações, 1948. 
Disponível em:

<http://www.ohchr.org/EN/UDHR/Documents/UDHR_Translations/por.pdf>. Acesso em: 31 jan. 2019.

POPPER, K. Conjecturas e refutações. Brasília: Unb, 1986.

RABENHORST, E. R. Necessidades básicas e direitos humanos. In: BITTAR, E. C. B.;

TOSI, G. (Org.). Democracia e Educação em Direitos Humanos numa época de insegurança. Brasília: Secretaria Especial dos Direitos Humanos da Presidência da República, 2008. p. 51-64.

ROSA, M. V. F. P. C; ARNOLDI, M. A. G. C. A entrevista na pesquisa qualitativa: mecanismos para validação dos resultados. Belo Horizonte: Autêntica, 2008.

SACAVINO, S. Educação em direitos humanos e democracia. In: CANDAU, V. M.; SACAVINO, S. (Org.). Educar em direitos humanos: construir democracia. Rio de Janeiro: DP\&A, 2000. p. 36-48.

. Que significa ser sujeito de direitos?. In: SACAVINO, S. B.; CANDAU, V. F. (Coord.). Educação e bullying. Rio de Janeiro: Novamerica/FA Studio Gráfico, 2012. p. 23-40.

SCHILLING, F. Direitos Humanos e Educação. São Paulo: Cortez, 2005.

SILVA, A. M. M. Direitos Humanos na Educação Básica: qual o significado?. In: SILVA, A. M. M.; TAVARES, C. (Org.). Políticas e fundamentos da educação em direitos humanos. São Paulo: Cortez, 2010. p. 41-63.

TEIXEIRA, B. B. Escolas para os direitos humanos e a democracia. In: SCHILLING, F. (Org.). Direitos Humanos e Educação. São Paulo: Cortez, 2005. p. 145-167.

TOSI, G. (Org.). Direitos Humanos: história, teoria e prática. João Pessoa: Editora Universitária, UFPB, 2005.

VIOLA, S. E. A. Políticas de Educação em Direitos Humanos. In: SILVA, A. M. M.; TAVARES, C. (Org.). Políticas e fundamentos da Educação em Direitos Humanos. São

Paulo: Cortez, 2010. p. 15-39.

; BARREIRA, C.; PIRES, T. V. Direitos humanos: de movimento social à proposta educativa. In: VIOLA, S. E. A.; ALBUQUERQUE, M. Z. (Org.).

Fundamentos para educação em direitos humanos. São Leopoldo: Sinodal, 2011. p. 143-156. 